Colloque C3, suppl. au Journal de Physique III, Vol. 1, octobre 1991

\title{
A MODIFIED KOLSKY METHOD FOR THE INVESTIGATION OF THE STRAIN-RATE HISTORY DEPENDENCE OF MECHANICAL PROPERTIES OF MATERIALS
}

\author{
A.M. BRAGOV, A.K. LOMUNOV and A.A. MEDVEDEV \\ State University of $N$. Novgorod, Gagarin avenue 23, Nizhni \\ Novgorod 603600, USSR
}

\begin{abstract}
Résumé : Une modification assez simple de la barre $d^{\prime}$ Hopkinson fendue (SHB) est présentée. Elle permet des extensions considérables de la méthode de kolsky dans l'étude de l'influence de la vitesse de déformation et de l'histoire de la vitesse de déformation sur les propriétés physiques et mécaniques des matériaux. Le développement de cette modification du SHB permet de conduire des essais incrémentaux avec chargement dynamique cyclique. Des exemples démontrant ces possibilités sont décrits.
\end{abstract}

\begin{abstract}
A fairly simple modification of the split Hopkinson bar (SHB) method is presented that extends significantly the scope of the Kolsky method in studying the effects of strain rate and strain-rate history on the physical and mechanical properties. The developed modification of the SHB method makes it possible to conduct incremental tests with alternating dynamic loading. Examples illustrating the possibilities of the modifications described are included.
\end{abstract}

In the recent three decades the SHB method, originally proposed by H. Kolsky, has been successfully used all over the world to study strain-rate dependence of the mechanical properties of structural materials. Presently, this method is used to determine the mechanical properties of materials loaded in tension, compression, torsion and shear [1] for the strain rates of $10^{3} \mathrm{~s}^{-1}$. In some works this method was used to study the efrects of strain-rate history on the mechanical properties of materials $[2-5]$. Most results of this kind have been obtained in the experiments where a dynamic load was superposed on a previously applied static one. There is a number of works where dynamic shifts from one strain rate to another were accomplished during high-rate loading of the specimen [5-6].

A Kolsky method modification that allowed to alternate the specimen loading and, thus, to study the dynamic Bauschinger effect was originally developed by Ogawa [7].

Some simple modifications of the SHB method have been worked out by the present authors to extend its scope.

To create complex strain-rate histories in specimens it is proposed to generate cyclic loads by loading the SHB system using projectiles made up of lengths of two or more bars of materials with different acoustic i mpedances $p C$, where $\rho$ is material density and $C$ is sound velocity in it. The bars the projectile is made up of may follow one another with no gaps between them $[8,9]$ (glued together) or with some gaps [10]. 
Using the bars of the first kind, one can generate, in the SHB system, compression pulses with a stepped loading pulse amplitude, and thus to study material response to a stepped strain-rate history. Projectiles of the second $k$ ind allow to form in the SHB a loading pulse sequence of different amplitudes with some intervals between them. Such projectiles are composed of two or more bars with different (or equal) acoustic impedances. The component bars of the composite projectile are connected by flexible, easy-to-deform brackets with their ends fixed in the slots provided at the bar ends facing each other. When a projectile is being accelerated in the gas gun bore, the brackets will not bend as the deformation is restricted retaining thus the initial spacing between the bars unchanged until the projectile hits the SHB. The projectile quitting the bore and impacting against the SHB, a compressive pulse of amplitude $\sigma_{1}$, proportional to the acoustic

impedance of the first component bar, is formed in the SHB. The termination of this pulse is followed by a complete unloading of the specimen. While the first pulse works, the second bar moves on inertially and impacts against the first one, creating in the SHB a new loading pulse (dynamic superposed load) of amplitude $\sigma_{2}$ that

depends on the acoustic impedance ratio of the first and the second bars. Depending on what the experiment is aimed at, the amplitude and duration of the pulses generated as well as the interval between them may be varied by adjusting the lengths and the acoustic impedances of the component bars and the spacing between them.

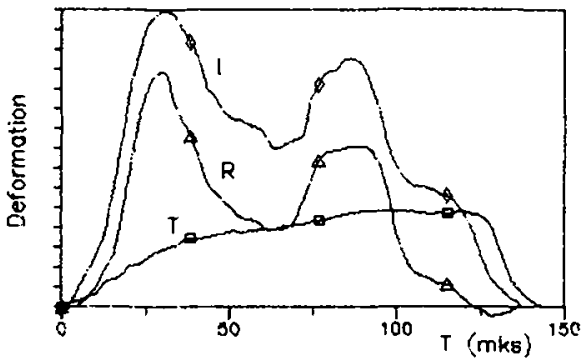

Fig. 1. The experimentol pulses in SHB by using the glued projectile

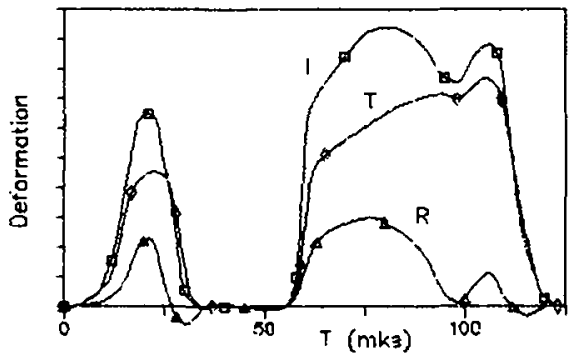

Fig. 2. The experimental puises in $\mathrm{SHB}$ by using the projectile with a gow

The oscilloscope traces of comressive pulses recorded in some of the experiments are shown in Figs. 1 and 2 . The left-hand curves are from the experiment with the projectile glued up of three parts: the middle part was made of D16T aluminum alloy while the first and the last ones were manufacturedof $30 x \Gamma C A$ steel. The use of such a projectile made it possible to change the strain rate in the course of the experiment rrom higher to lower and vice versa. The right-hand curves were obtained when loading the SHB by a spaced composite projectile with the first part made of D1ET alloy and the second one made of 30XГCA steel. In the above test the delay between the loading cycles was $20 \mu \mathrm{s}$, the strain rate at the second stage being about twice the first one.

Fig. 3 shows the deformation curves for AD1 al uminum obtained when loading the SHB by a projectile glued up of three parts. Shifts from a lower strain rate to a higher one and vice versa were accomplished in the experiments. The results are compared with the constant-rate curves (dotted curves in the figure). It is evident that aluminum responds quickly enough to the changes in strain rate and is at the 
same tume fairly sensitive to the deformation history (the curves for strain-rate jumps do not reach the ones for constant values of strain rate). the sensitivity increasing with the decrease of the strain rate Fig. 4 shows the deformation curves for ADO aluminum obtained for the SHB loaded by the projectile of the second kind. The results suggest that unloading of the specimen after the first loading cycle, and the following second loading, are elastic, the elastic modulus being equal to the initial Young's modulus of the material. Plasticity is reached after a 20 Hs hold, at the stresses higher than those at the beginning of the unloading (with the increased strain rate in the second cycle). In what follows the deformation curve,, after the second load, approaches the curve obtained for an equal, but a constant rate.
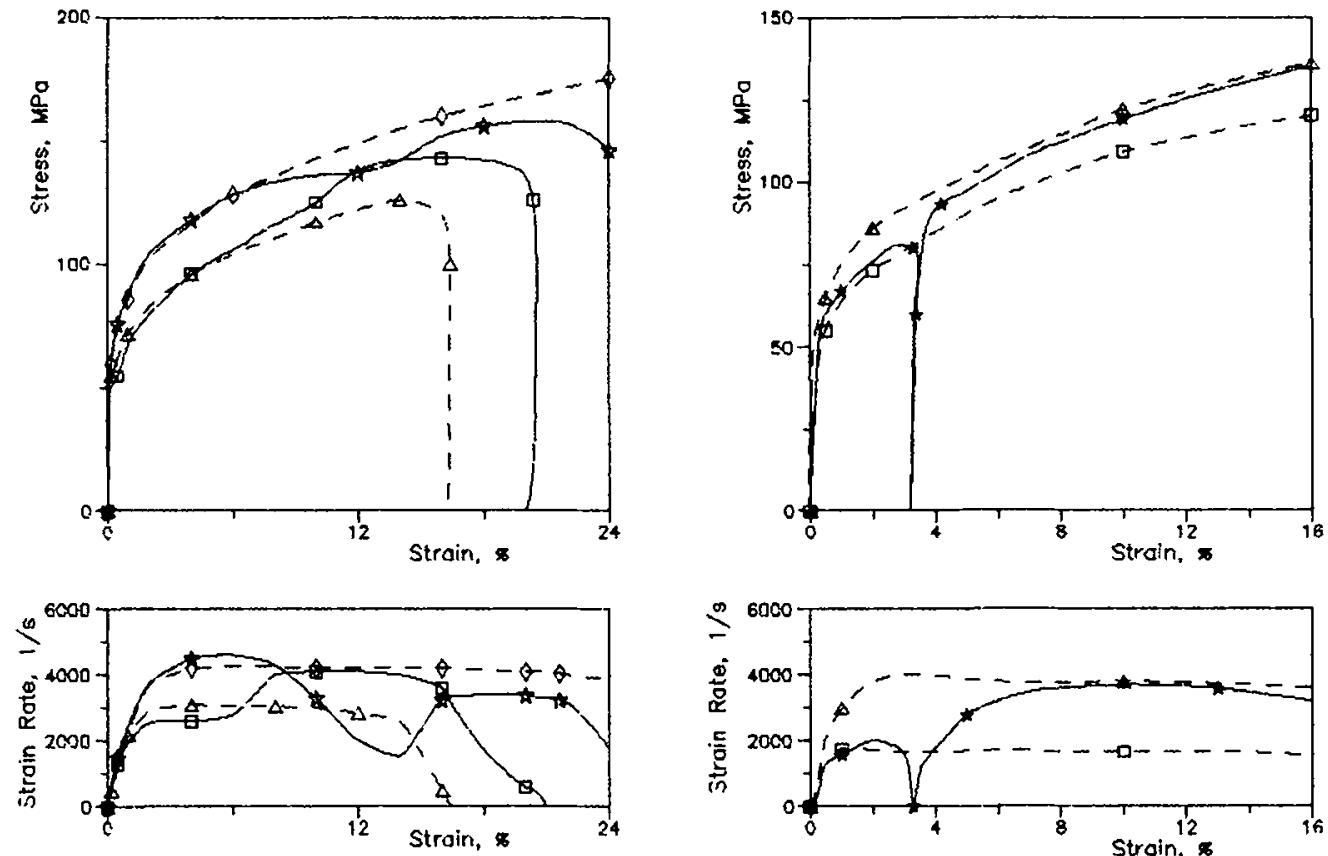

Fig. 3. Deformation curves for A01 oluminum wher loaded using gived projectrles

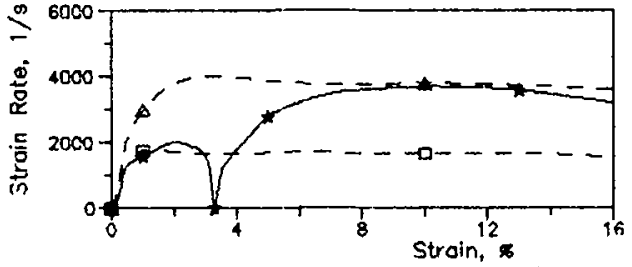

Fia. 4. Deformotion curves for $A D O$ aluminum when looded using projectiles with a gop

To study material behaviour under alternating dynamic loading, an extensional SHB modification is used [11-12]. Its main difference from the Nicholas scheme [13] consists in the absence of a shoulder inserted between the ends of the pressure bars around the specimen. So between the ends of the bars a small gap is created, providing an additional compressive cycle for the specimen before a rountine extensional cycle. Two versions of a threaded joint between the specimen and the pressure bars are proposed:

- a hollow specimen is screwed upon the ends of the bars whose butts having a smaller diameter create, inside the specimen, a small gap that 1 imits the specimen deformation under compression (Fig. 5);

- a solid specimen is screwed into the bar ends, so as to create a gap between them (Fig. 6 ).

When a compressive loading pulse in the incident bar reaches the specimen, a portion of the pulse is reflected, while some part is transmitted through the specimen into the second bar. This is the first cycle of specimen loading in compression. The specimen 
compressive strain magnitude is deterinined by the size of the gap between the bar ends. It should be noted that until the gap is reduced to zero, the amplitude of the wave traversing the specimen is equal to a portion of the incident pulse amplitude. This portion is determined by a hardening mode and a cross section area of the specimen tested. Upon reaching a certain value of a compressive strain by the specimen, the bar ends come into contact and the rest of the incident wave passes over to the transmitter bar with its amplitude practicaliy unchanged. The plastic strain value, after the bars have come into contact, remains constant during the life of the rest of the original pulse. After that unloading of the specimen takes place. Stress values drop to zero, the total strain is reduced by the elastic component value, thus, bringing the bar ends out of contact. Then the transmitted compression wave is reflected from the free end of the second bar as the tension wave. That is the second cycle of specimen extension loading which is similar to the Nicholas experimerit.

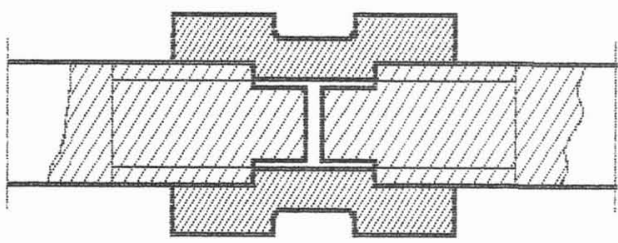

Fig. 5. Hollow specimen attachment pattern

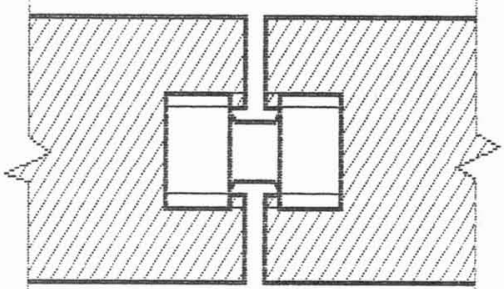

Fig. 6. Solid specimen attachment pattern

As the incident bar is twice as long as the transmitter one, thesuperposition of pulses during the second cycle is avoided. Thus, the proposed modification allows creating two deformation cycles for the specimen in compression and in tension, the loading pulse amplitudes being equal in the first and the second cycles.

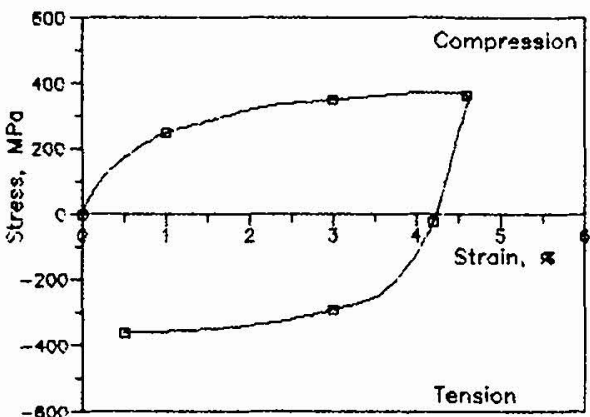

Fig. 7. Coformation curvers for D16T oluminum alley under alternating loading

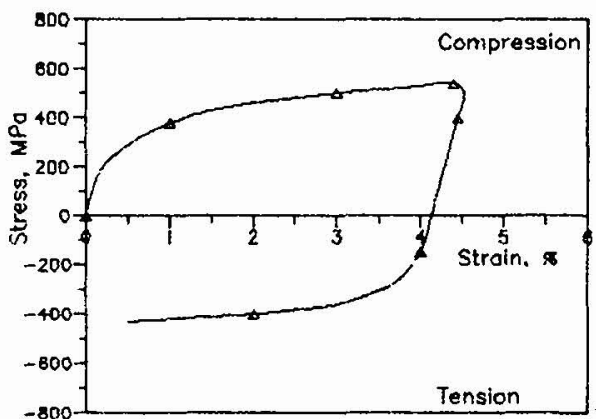

Fig. 8. Deformation surves for $M 1$ scpper under alternating looding

As an example of applying the SHB method to studying the material behaviour under alternating dynamic loading Figs. 7 and 8 show deformation histories for the D16T aluminum alloy and the M1 copper. 
Thus the proposed simple modifications of the SHB method allow to extend significantly its scope in the investigation of the strain-rate history dependence of mechanical properties of structural materials.

\section{REFERENCES}

1/ Nicholas $T$., in Impact Dynamics, J.A. Zukas, T. Nicholas, H. F. Swift, L. B. Greszczuk, D. R. Curran (Eds.). Hiley-Interscience, N. Y. , 1982.

a, Wu H.C., Yip M.C., Int. J. Solids Struct. . 16, (1980), 515.

3) Duffy J., in Mechanical Properties at High Rates of Strain, J.Harding (Ed.), Institute of Physycs, London, 1980, p. 1.

/4/ Klepaczko J., Duff́y J., Archives of Mechanics, 34, (1982), $N 4$, p. 419.

5/ Lipkin J., Campbell J.D. , Swearengen J.C., J. Mech. Phys. Solids, 26, (1978), N 4, P. 251 .

16/ Lindholm U.S., J. Mech. Phys. Solids, 12, (1964), N 4, p. 317.

7/ Cgawa K., Exp. Mech., 24, (1984), N 2, p. 81.

18/ Author's certificate of the USSR No $1182328 . \mathrm{G} 01 \mathrm{~N} 3 / 30$. (1985).

19/ Bragov A.M., Lomunov A.K., in Prikladnye Problemy Prochnosty $i$ Plastichnosty, Vsesouz. Mezhvuz. Sb., Gorky University, (1985), p. 131 .

10/ Author's certificate of the USSR No 1293545. $G$ O1 $N 3 / 30$, G $01 \mathrm{M} 7 / 00$, (1987).

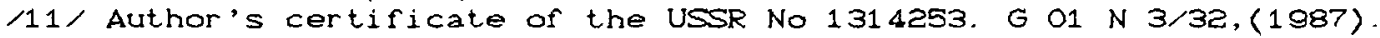

12, Bragov A. M. , Lomunov A.K., Medveder A. A., in Prikladnye Problemy Prochnosty i Plastichnosty, Vsesouz. Mezhvuz. Sb., Gorky University, (1987), p. 90.

113/ Nichol as T., Exp. Mech., 21, (1881), N 5, p. 177. 